\title{
Coexistence of Impairment of Endothelium-Derived Nitric Oxide and Platelet-Derived Nitric Oxide in Patients With Coronary Risk Factors
}

\author{
Atsushi Katoh, MD; Hisao Ikeda, MD; Yoshinori Takajo, MD; \\ Nobuya Haramaki, MD; Toyoaki Murohara, MD; Satoshi Shintani, MD; \\ Seiji Kanaya, MD; Shinji Yokoyama, MD; Takafumi Ueno, MD; \\ Tomoki Honma, MD; Tsutomu Imaizumi, MD
}

\begin{abstract}
Impairment of endothelium-derived nitric oxide (EDNO) has been demonstrated in patients with coronary risk factors in some studies, as well as impaired platelet-derived nitric oxide (PDNO) in other studies. However, no study has examined whether these impairments coexist. In 24 patients with coronary risk factors, femoral vascular endothelial function was assessed with acetylcholine (ACh: 50, 100, 200 and 400 $\mathrm{g} / \mathrm{min}$ ) and endothelium-independent vascular function with nitroglycerin (NTG; 50, 100, 200 $\mathrm{g} / \mathrm{min}$ ) using a Doppler flow-wire technique, as well as ADP $(5 \mu \mathrm{mol} / \mathrm{L})$-induced PDNO release with an NO-specific electrode. The ACh-mediated percent change in femoral vascular resistance index (\% change of FVRI) and PDNO release had a significant correlation with the number of risk factors. The ACh-mediated \% change of FVRI, but not that with NTG, significantly correlated with the PDNO release. Both EDNO and PDNO bioactivities are impaired in patients with coronary risk factors and there is a common mechanism. (Circ J 2002; 66: 837-840)
\end{abstract}

Key Words: Bioactivity; Endothelium; Nitric oxide; Platelets; Risk factors

$\mathbf{E}$ ndothelium-derived nitric oxide (EDNO), which accounts for the major biological properties of the endothelium-derived relaxing factor, is synthesized from L-arginine via NO synthase (NOS)? NO is a single molecule with profound effects on cardiovascular physiology: it inhibits pathologic processes such as abnormal arterial vasomotion, thrombosis, and vascular smooth muscle cell proliferation ${ }^{3-5}$ In humans, platelet-derived NO (PDNO) is also produced by the L-arginine/NO pathway through constitutive NOS6 Platelet aggregation is inhibited by L-arginine, a precursor of NO, potentiated by NGmonomethyl-L-arginine, an inhibitor of NOS, 6,7 and is accompanied by an increase in intracellular cyclic guanosine 3', 5'-monophosphate, 6 , PDNO release during platelet aggregation is now recognized as a negative-feedback mechanism to inhibit not only platelet aggregation ${ }^{8}$ but also platelet recruitment?

Coronary risk factors are known to impair both EDNO ${ }^{10-12}$ and PDNO; $7,13,14$ however, there has not been a study measuring both EDNO and PDNO simultaneously in the same subjects, so it is still unknown whether impairment of these bioactivities coexist. Therefore, we investigated the relationship between EDNO and PDNO in patients with coronary risk factors.
(Received February 20, 2002; revised manuscript received June 10, 2002; accepted June 21, 2002)

Department of Internal Medicine III and the Cardiovascular Research Institute, Kurume University School of Medicine, Kurume, Japan

Mailing address: Hisao Ikeda, MD, PhD, Department of Internal Medicine III, Kurume University School of Medicine, 67 Asahi-machi, Kurume 830-0011, Japan. E-mail: ikeikeda@med.kurume-u.ac.jp

\begin{abstract}
Methods
Study Patients

The study group comprised 24 patients ( 17 men, 7 women; mean age, 67 years; range, 46-78 years) who underwent diagnostic cardiac catheterization and coronary arteriography. Femoral arterial endothelial function and PDNO release were studied in all patients. All cardiovascular medications were withheld for at least $72 \mathrm{~h}$ before the study. None of the patients had acute coronary syndromes, heart failure, or valvular heart disease. The study was approved by the institutional ethical committee, and written informed consent was obtained from all patients.

The coronary risk factors were hypertension (arterial blood pressure $\geq 140 / 90 \mathrm{mmHg}$ ), hypercholesterolemia (total serum cholesterol $\geq 220 \mathrm{mg} / \mathrm{dl}$ ), current smoking (subjects who smoked $\geq 15$ cigarettes per day for $\geq 5$ years), diabetes mellitus (fasting glucose $\geq 126 \mathrm{mg} / \mathrm{dl}$ and/or plasma glucose $\geq 200 \mathrm{mg} / \mathrm{dl} 2 \mathrm{~h}$ after glucose administration), age (men $\geq 45$ years old, women $\geq 55$ years old or postmenopausal), 5 and a family history of coronary artery disease. Family history was considered positive if a firstdegree relative had clinical evidence of coronary artery disease at less than 55 years of age in male relatives or less than 65 years in female relatives! 15
\end{abstract}

\section{Assessment of Femoral Arterial Function}

After cardiac catheterization, femoral arterial endothelial function was assessed using a Doppler flow-wire technique as previously described $!^{16}$ Briefly, a $5 \mathrm{~F}$ angiographic catheter was introduced $1 \mathrm{~cm}$ beyond the end of a $6 \mathrm{~F}$ femoral artery sheath and then a 0.018-in Doppler flow-wire (Cardiometrics Inc) was introduced through the catheter to $1 \mathrm{~cm}$ beyond the catheter tip to obtain an adequate flow velocity 
Table 1 Patients Characteristics

\begin{tabular}{lc}
\hline \hline Age $($ years $)$ & $66 \pm 7$ \\
Gender $(\mathrm{M} / \mathrm{F})$ & $17 / 7$ \\
Total choresterol level $(\mathrm{mg} / \mathrm{dl})$ & $192 \pm 32$ \\
LDL choresterol level $(\mathrm{mg} / \mathrm{dl})$ & $117 \pm 29$ \\
HDL choresterol level $(\mathrm{mg} / \mathrm{dl})$ & $50 \pm 14$ \\
Mean arterial pressure $(\mathrm{mmHg})$ & $96 \pm 12$ \\
Hypercholeterolemia, $n(\%)$ & $9(38)$ \\
Hypertension, $n(\%)$ & $11(46)$ \\
Diabetes mellitus, $n(\%)$ & $9(38)$ \\
Previous smoking, $n(\%)$ & $7(29)$ \\
Family history of coronary artery disease, $n(\%)$ & $1(4)$ \\
\hline
\end{tabular}

signal. Drugs were then infused through the sheath. A femoral angiogram was performed to exclude obstructive disease in the femoral circulation. The average peak veloity during each intervention was recorded. Because diameter measurements were not made at the level of the Doppler wire with each intervention, we calculated the femoral vascular resistance index (FVRI, $\mathrm{mmHg} \cdot \mathrm{cm}^{-1} \cdot \mathrm{s}^{-1}$ ) as the mean arterial pressure divided by femoral blood flow velocity. To exclude any significant changes in femoral artery diameter at the site of the flow wire during conditions of increased blood flow, we measured femoral artery diameter at the site of the flow wire during administration of acetylcholine (ACh; 400 $\mathrm{g} / \mathrm{min}$ ) and nitroglycerine (NTG; $200 \mu \mathrm{g} / \mathrm{min}$ ) in 10 patients. There was no significant change in femoral artery diameter at the site of the flow wire during these drug infusions: baseline, $4.8 \pm 0.7 \mathrm{~mm}, \mathrm{ACh}, 4.8 \pm$ $0.7 \mathrm{~mm}$ and NTG, $4.8 \pm 0.7 \mathrm{~mm}$ (all $\mathrm{p}=\mathrm{NS}$ compared with baseline).

After the baseline measurements of flow velocity and mean arterial blood pressure, 2-min serial infusions of ACh at 50,100, 200 and $400 \mu \mathrm{g} / \mathrm{min}$ were performed. After recovery and return to baseline values, NTG was serially administered at 50, 100 and $200 \mu \mathrm{g} / \mathrm{min}$ for $3 \mathrm{~min}$. Peak flow velocity and arterial blood pressure were measured after each intervention.

\section{Preparation of Gel-Filtered Platelets}

Peripheral venous blood $(20 \mathrm{ml})$ was drawn before examination of the FVRI, and gel-filtered platelets were prepared as described previously? Briefly, the citrated blood was centrifuged $\left(150 \mathrm{G}, 15 \mathrm{~min}, 22^{\circ} \mathrm{C}\right)$ and the platelet-rich plasma was separated and passed over a Sepharose-2B column equilibrated with HEPES-Tyrode's buffer without $\mathrm{Ca}^{2+}$. The platelet counts were finally adjusted to $2 \times 10^{5}$ platelets $\mu \mathrm{L}$ in Tyrode's solution.

\section{Measurements of PDNO With an NO-Specific Electrode}

We measured PDNO using an electronic NO meter (Model N0-501, Inter Medical Co) as described previously?,13,14 The NO meter and electrodes were placed in an electromagnetic shield box to avoid electrical perturbation. The electrodes were placed in the chamber containing the gel-filtered platelets and after the addition of $\mathrm{Ca}^{2+}$ and fibrinogen, followed by $\operatorname{ADP}(5 \mu \mathrm{mol} / \mathrm{ml})$, the working electrode was supplied with $+0.6 \mathrm{~V}$ for electrochemical oxidation of NO. The change in the peak electrical current was considered the index of NO release.

\section{Statistical Analysis}

Data are expressed as mean \pm SD. The relationship between 2 parameters was analyzed by linear regression.
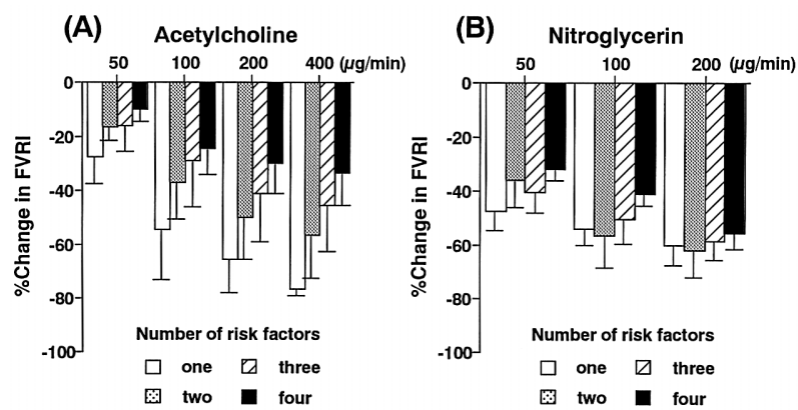

(C)

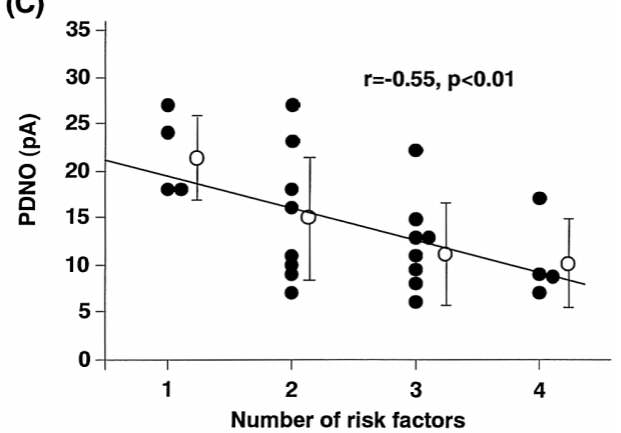

Fig 1. Relationship between femoral arterial responses to acetylcholine (ACh) (A) and nitroglycerin (NTG) (B) and the number of coronary risk factors. ACh-mediated changes, but not those with NTG, in the femoral vascular resistance index (FVRI) correlated with the number of coronary risk factors. In the relationship between platelet-derived $\mathrm{NO}(\mathrm{PDNO})$ release and the number of coronary risk factors $(\mathrm{C})$, there was a correlation.

Statistical significance was considered at $\mathrm{p}<0.05$.

\section{Results}

\section{Clinical Characteristics (Table 1)}

The mean number of risk factors was $2.5 \pm 1.0$, and the composite risk factor was 1 in 4 patients, 2 in 8, 3 in 8, and 4 in 4.

\section{Vascular Responses and Coronary Risk Factors}

ACh-mediated changes in the FVRI significantly correlated with the number of risk factors $(\mathrm{r}=-0.53, \mathrm{p}<0.01 ; \mathrm{r}=$ $-0.54, \mathrm{p}<0.01 ; \mathrm{r}=-0.61, \mathrm{p}<0.01$; and $\mathrm{r}=-0.70, \mathrm{p}<0.01$ at 50 , 100,200 , and $400 \mu \mathrm{g} / \mathrm{min}$ of ACh, respectively (Fig $1 \mathrm{~A}$ ), but the NTG-mediated changes did not (Fig 1B).

\section{PDNO Release and Coronary Risk Factors}

Mean PDNO was $14.5 \pm 6.5 \mathrm{pA}$ (range 6-27 pA), and PDNO release negatively correlated with the number of risk factors ( $\mathrm{r}=-0.55, \mathrm{p}<0.01$; Fig $1 \mathrm{C}$ ).

\section{Relationship Between Vascular Responses and PDNO Release}

PDNO release significantly correlated with the AChmediated changes in FVRI at 50, 100, 200, and 400 $\mathrm{g} / \mathrm{min}$ of ACh (Fig 2). PDNO release did not correlate with the NTG-mediated changes (data not shown).

\section{Discussion}

ACh is commonly used as a probe for evaluating endothelial function, especially EDNO releasing capac- 

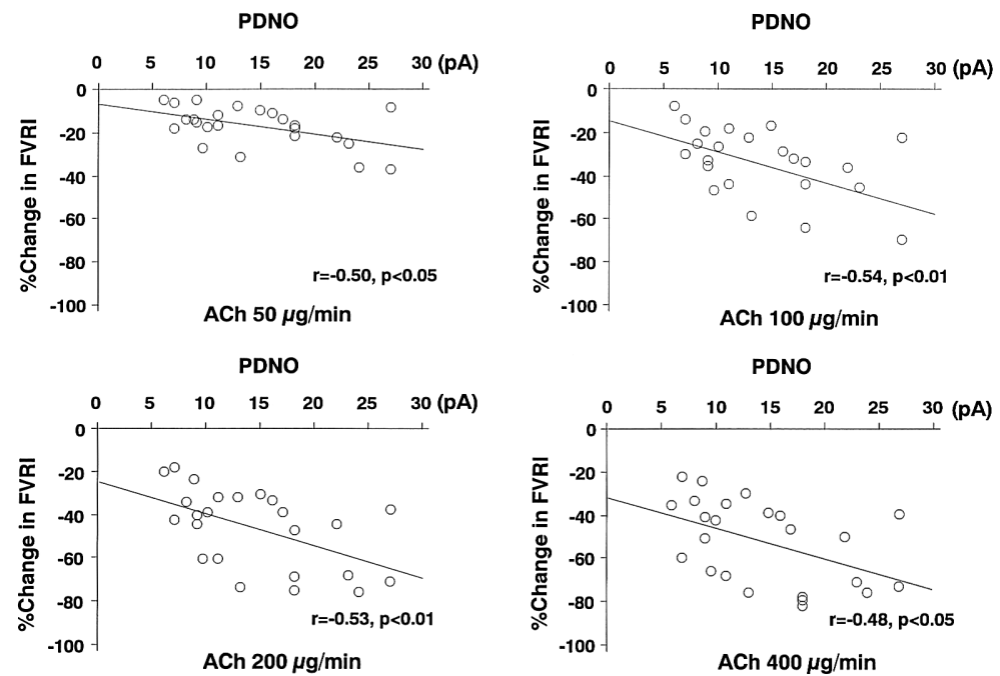

Fig 2. Relationship between femoral arterial responses to acetylcholine (ACh) and plateletderived NO (PDNO) release in patients with coronary risk factors. PDNO release was correlated with ACh-mediated changes in the femoral vascular resistance index (FVRI).

ity, 1,2 and NTG is used to test endothelium-independent vasodilator function in humans. In previous studies, the number of coronary risk factors has correlated with impaired ACh-mediated vasodilation in patients with coronary atherosclerosis and risk factors, ${ }^{10-12}$ and we had a similar result in the human femoral circulation. This abnormality is usually attributed to decreased EDNO, which is synthesized from L-arginine via NOS in the endothelial cells. An NO-selective electrode is specifically capable of measuring real-time release of $\mathrm{NO}$ from aggregating platelets, 77 and we have previously confirmed that the change in the electrical current obtained by the NO-selective electrode reflects the amount of NO released through the L-arginine/NO pathway in aggregating human platelets? Recently, we demonstrated that the number of coronary risk factors correlates with the degree of an impairment of PDNO release by human platelets ${ }^{13}$ and we had a similar finding in the present study. All these findings suggest that the L-arginine/NO pathway, which is a negative feedback mechanism that inhibits platelet aggregation, is indeed impaired in patients with coronary risk factors. Thus, both EDNO and PDNO bioactivities are more impaired when there are more risk factors. Importantly, ACh-mediated changes in the FVRI were significantly related to PDNO release and taken together, to the best of our knowledge, our data are the first demonstration that EDNO and PDNO are correlated in humans, and that the Larginine/NO pathway is impaired in both endothelial cells and platelets in patients with coronary risk factors.

The underlying mechanisms are still unknown, but these impairments may be explained by increased oxidative stress as a common cascade, which impairs the release of $\mathrm{NO}$ or augments the inactivation of NO in patients with coronary risk factors 3,18 Indeed, we have previously shown that impaired PDNO bioactivity and augmented platelet aggregability in smokers may be caused by an imbalance of the intraplatelet redox state through increased oxidative stress ${ }^{14,19}$ In general, EDNO and PDNO act in coordination as anti-atherothrombogenic molecules, $3,4,8,9$ and in the previous clinical studies, impaired EDNO or PDNO has been associated with an increase in cardiovascular events such as acute coronary syndromes?20,21 Accordingly, impaired EDNO and PDNO bioactivities may synergistically contribute to atherothrombogenesis in patients with coronary risk factors.

\section{Study Limitations}

First, the relatively small number of the subjects might have affected the results, but despite this, a significant correlation was found between EDNO and PDNO. Second, the contributions of endothelium-derived hyperpolarization factor and other vasodilating factors to ACh-induced vasodilation were not considered, but it has been demonstrated that the vasodilating effect of ACh is mainly caused by EDNO?2

In conclusion, we have contributed to the understanding of the pathophysiology of atherothrombosis by demonstrating that both EDNO and PDNO bioactivities are impaired in patients with coronary risk factors, which suggests that both are involved in atherogenesis.

\section{Acknowledgments}

This study was supported in part by a grant-in-aid for scientific research from the Ministry of Education, Science, Sports and Culture of Japan, Tokyo and by a research grant from the Kimura Memorial Heart Foundation, Kurume, Japan. The authors are very grateful to Kimiko Kimura for her excellent technical assistance.

\section{References}

1. Furchgott RF, Zawadzki JV. The obligatory role of endothelial cells in the relaxation of arterial smooth muscle by acetylcholine. Nature 1980; 288: $373-376$

2. Palmer RMJ, Ashton DS, Moncada S. Vascular endothelial cells synthesize nitric oxide from L-arginine. Nature 1988; 333: 664666.

3. Harrison DG. Cellular and molecular mechanisms of endothelial cell dysfunction. J Clin Invest 1997; 100: 2153-2157.

4. Cooke JP, Dzau VJ. Nitric oxide synthase: Role in the genesis of vascular disease. Annu Rev Med 1997; 48: 489-509.

5. Egashira K. Clinical importance of endothelial function in arteriosclerosis and ischemic heart disease. Circ J 2002; 66: 529-533.

6. Radomski MW, Palmer RMJ, Moncada S. An L-arginine/nitric oxide pathway present in human platelets regulates aggregation. Proc Natl Acad. Sci USA 1990; 87: 5193-5197.

7. Ichiki $\mathrm{K}$, Ikeda $\mathrm{H}$, Haramaki $\mathrm{N}$, Ueno $\mathrm{T}$, Imaizumi T. Long-term smoking impaired platelet-derived nitric oxide release. Circulation 1996; 94: 3109-3114.

8. Moncada S, Palmer RMJ, Higgs EA. Nitric oxide: Physiology, pathophysiology, and pharmacology. Pharmacol Rev 1991; 43: $109-142$.

9. Freedman JE, Michelson AM, Barnard MR, Alpert C, Keaney JFJ, Loscalzo J. Nitric oxide release from activated platelets inhibits 
platelet recruitment. J Clin Invest 1997; 100: 350-356.

10. Vita JA, Treasure CB, Nabel EG, Mclenachan JM, David FR, Yeung $\mathrm{AC}$, et al. Coronary vasomotor response to acetylcholine relates to risk factors for coronary artery disease. Circulation 1990; 81: 491497.

11. Egashira K, Inou T, Hirooka Y, Yamada A, Maruoka Y, Kai H, et al. Impaired coronary blood flow response to acetylcholine in patients with coronary risk factors and proximal atherosclerotic lesions. $J$ Clin Invest 1993; 91: 29-37.

12. Quyyumi AA, Dakak N, Andrews NP, Husain S, Arosa S, Gilligan DM, et al. Nitric oxide activity in the human coronary circulation: Impact of risk factors for coronary atherosclerosis. J Clin Invest 1995; 95: $1747-1755$.

13. Ikeda H, Takajo Y, Murohara T, Ichiki K, Adachi H, Haramaki N, et al. Platelet-derived nitric oxide and coronary risk factors. Hypertension 2000; 35: 904-907.

14. Takajo $\mathrm{Y}$, Ikeda $\mathrm{H}$, Haramaki $\mathrm{N}$, Murohara $\mathrm{T}$, Imaizumi $\mathrm{T}$. Augmented oxidative stress of platelets in chronic smokers: Mechanisms of impaired platelet-derived nitric oxide bioactivity and augmented platelet aggregability. J Am Coll Cardiol 2001; 38: $1320-1327$

15. Grundy SM, Balady GJ, Criqui MH, Fletcher G, Greenland P, Hiratzka LF, et al. Guide to primary prevention of cardiovascular diseases: A statement for healthcare professionals from the task force on risk reduction. Circulation 1997; 95: 2329-2331.

16. Husain S, Andrews NP, Mulcahy D, Panza JA, Quyyumi AA. Aspirin improves endothelial dysfunction in atherosclerosis. Circulation 1998; 97: 716-720.

17. Malinski T, Radomski MW, Taha Z, Moncada S. Direct electrochemical measurement of nitric oxide released from human platelets. Biochem Biophys Res Commun 1993; 194: 960-965.

18. Nakaishi T, Tamura A, Watanabe T, Mikuriya Y, Nasu M. Relationship between plasma oxidized low-density lipoprotein and the coronary vasomotor response to acetylcholine in patients with coronary artery disease. Jpn Circ J 2000; 64: 856-860.

19. Haramaki N, Ikeda H, Takajo Y, Katoh A, Kanaya S, Shintani S, et al. Long-term smoking causes nitroglycerin resistance in platelets by depletion of intraplatelet glutathione. Arterioscler Thromb Vasc Biol 2001; 21: 1852-1856.

20. Schächinger V, Britten MB, Zeiher AM. Prognostic impact of coronary vasodilator dysfunction on adverse long-term outcome of coronary heart disease. Circulation 2000; 101: 1899-1906.

21. Freedman JE, Ting B, Hankin B, Loscalzo J, Keaney JF, Vita JA. Impaired platelet production of nitric oxide predicts presence of acute coronary syndromes. Circulation 1998; 98: 1481-1486.

22. Prasad A, Husain S, Quyyumi AA. Effect of enalaprilat on nitric oxide activity in coronary artery disease. Am J Cardiol. 1999; 84: 16. 